
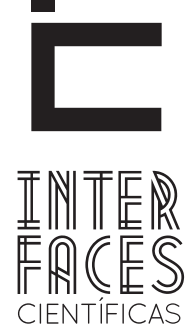

DIREITO

ISSN IMPRESSO 2316-3321

E - ISSN 2316-381X

DOI - 10.17564/2316-381X.2017v6n1p75-86

\title{
EL ASCENSO POLLTICO DE LA CONTRA-ÉLITE LIDERADA POR EVO MORALES
}

\author{
A ASCENSÃO POĹTICA DA CONTRA-ELLTE LIDERADA POR EVO MORALES \\ THE POLTICAL RISE OF THE COUNTER-ELTELED BY EVO MORALES
}

Fran Espinoza ${ }^{1}$
Dirceu André Gerardi

Amanda Sangalli²

\section{RESUMEN}

Las investigaciones que analizan el escenario político y social boliviano, se centran en la capacidad movilizadora y de resistencia de las federaciones de cocaleros frente a la represión del Estado; sin embargo, se hace poca reflexión sobre las estrategias políticas de la contra-élite liderada por Evo Morales. El presente artículo tiene como objetivo describir el ascenso político de Evo Morales desde la perspectiva de los estudios elitarios. En ese sentido, se manejará la siguiente definición de contra-élite: grupos o estratos sociales que quieren conquistar el poder y tienen intereses e ideas alternativas a la élite gobernante. Se parte del supuesto que el triunfo electoral de Evo Morales se debe a cálculos políticos en su afán por el reparto de poder. A nivel metodológico, se estudia los principales acontecimientos sociales que propiciaron su victoria. Se concluye que la fortaleza de la contra-élite radica en construcción de los vínculos entre movimientos y partido político.

\section{PALABRAS CLAVES}

Bolivia. Contra-élite. Cocaleros. Evo Morales. Movimientos Sociales. Partidos Políticos. 


\section{RESUMO}

As pesquisas que tratam sobre o cenário político e social boliviano são direcionadas à capacidade mobilizadora e deresistência das federações de cocaleiros frente à repressão do Estado. Entretanto, há pouca reflexão sobre as estratégias políticas da contra-elite liderada por Evo Morales. Este artigo tem como objetivo é descrever a ascensão política de Evo Morales através da perspectiva do estudo das elites. Deste modo, se trata da seguinte definição de contra-elite: grupos ou estratos sociais que querem conquistar o poder e tem interesses e ideias alternativas à da elite governante. Supõe-se que o triunfo eleitoral de Evo Morales se deve a cálculos políticos em busca pela

\section{ABSTRACT}

The researches about the Bolivian political and social scene are directed at the mobilization and resistance capacity of the coca growers' federations in the face of State repression. However, there is little reflection on the political strategies of the counter-elite led by Evo Morales. This article describe the political rise of Evo Morales through the perspective of the study of elites. Thus, the definition of counter-elite is: groups or social strata that want to gain power having interests and alternative ideas to that of the ruling elite. It is assumed that Evo Morales electoral triumph is due to political calculations in search of power sharing. At partilha do poder. A nível metodológico, se estuda os principais acontecimentos sociais que proporcionaram sua vitória. Se conclui que os pontos fortes da contra-elite estão na construção dos vínculos entre movimentos e partido político.

\section{PALAVRAS-CHAVES}

Bolivia, contra-elite, cocaleiros, Evo Morales, movimentos sociais, partido político.

the methodological level, one studies the main social events that provided its victory. I conclude the counter-elite's strengths lie in building the links between social movements and political parties.

\section{KEYWORDS}

Bolivia. Counter-elite. Coca growers'. Evo Morales. Social movements. Political parties. 


\section{INTRODUCCIÓN}

En el escenario político de los años 1980 convergieron una serie de acontecimientos que propician el surgimiento de la contra-élite. El liderazgo personal de Morales, hizo que los movimientos sociales tomaran conciencia de los privilegios que disfrutaban las viejas élites. En 1993, Morales había considerado su postulación a candidato presidencial. En 1997 cuando el sistema electoral permitió el ingreso de diputados por voto directo inició su carrera política y su afán por la lucha del reparto de poder.

El presente artículo tiene como objetivo describir la trayectoria político social de Evo Morales, introduciendo la categoría de análisis contra-élite.

En ese marco, se manejará la definición de Waldmann (2007), contra-élite son grupos o estratos sociales que quieren conquistar el poder y tienen intereses e ideas alternativas a la élite gobernante. Pueden salir de cierta generación o institución, formarse abiertamente o en secreto, articular sus reclamos a través de un partido nuevo o en protestas sociales. La categoría de análisis, propuesta por Espinoza (2015), sostiene en el proceso de articulación política, los líderes de la contra-élite consideran al menos dos opciones: (i) generar más protesta para que la antigua élite de respuesta a sus demandas; y/o (ii) luchar por el reparto del poder incrementando la presión social con protestas cristalizándose como partido político.

Por las características del presente trabajo, nuestro estudio se centrará en la visión sociológica ${ }^{1}$. Se manejara la siguiente hipótesis: el triunfo electoral de Evo Morales se debe a cálculos políticos en su afán por el reparto de poder. El documento se estructura en cinco partes, en la primera parte se expone la conflictividad social causada por las políticas de erradicación de la hoja de coca. Luego, en la segunda parte, se explica el origen social de Evo Morales. En la tercera parte, se analiza la articulación entre el liderazgo sindical y la carrera política de Evo Morales. En la cuarta

1. Para profundizar en la vía electoral veáse: Movilizaciones sociales y partidos políticos: las vías de la contra-élite en Bolivia y Ecuador (ESPINOZA; FRANZ JUNIOR, 2016). parte, se estudia una de las principales fortaleza de la contra-élite, la lucha social en la calle. Por último, en la quinta parte se presentan la conclusión.

\section{LA LUCHA POR LA DEFENSA DE LA "HOJA SAGRADA"}

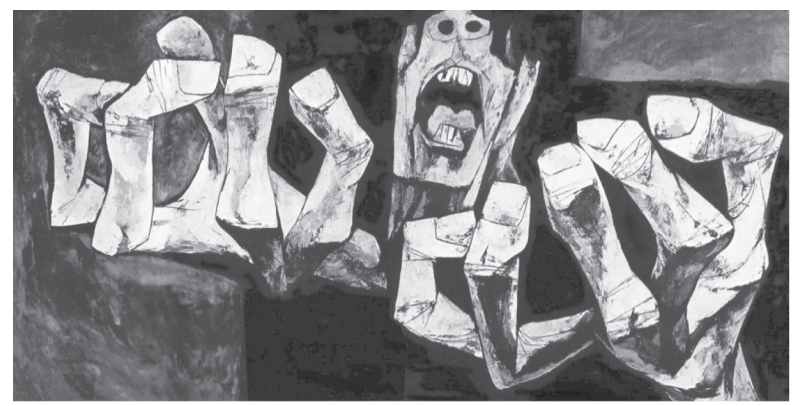

Las manos de la protesta, Guayasamin.

Desde inicios de los años 1980, el "contrapoder" boliviano fue liderado por las federaciones de cocaleros, conformadas por campesinos que se habían trasladado a la región tropical amazónica del Chapare con la intención de establecer sus colonias y arraigar su modelo de vida a los productos tropicales. La principal fortaleza de los nuevos pobladores era la presencia de algunos ex-obreros de las minas y campesinos con experiencia en la organización sindical. El liderazgo les permitió hacerse cargo de las principales decisiones de la comunidad: la distribución de la tierra y la instalación de servicios básicos.

El número de cocaleros se incrementó con dos olas migratorias. Los campesinos del altiplano se vieron forzados a abandonar sus tierras debido a la sequía de 1983 y al desmantelamiento de la Corporación Minera de Bolivia (COMIBOL), causado por las primeras reformas neoliberales de 1985, las cuales produjeron el cierra de innumerables minas y el despido, eufemísti- 
camente llamado relocalización de más de veinte mil minas (DO ALTO, 2007, p. 26).

[...] la falta de oportunidades de la población del altiplano y los valles altos, era un incentivo para que los campesinos migraran al Chapare buscando mejores horizontes, participando en la economía y mercado de la coca Entre los años 70 y 80 con el "boom" de la cocaína también hay el "boom" de la inmigración de mano de obra a esta zona. En las provincias de Chapare y Carrasco, de 1967 a 1989 la población aumentó de 24.381 a 350.000 habitantes. (PÉREZ, 1992, p. 28).

La "hoja sagrada" se había vuelto famosa por el aumento de la producción de la cocaína. Durante la dictadura de Luis García Meza (1980-1981), la economía nacional vinculada a la cocaína vivió una época dorada a tal punto que llegó a representar más del 50\% del PIB (DO ALTO, 2007, p. 25-43).

La ley 1008 del año 1988, sirvió de marco legal para las políticas de erradicación a la vez que propició la participación política del movimiento cocalero (DO ALTO, 2007, p. 27). La ley regulaba las políticas estatales frente a la coca, también sirvió para sustentar algunas políticas gubernamentales como El Plan de Acción Inmediata Opción Cero de 1994 y el Plan por la Dignidad de 1997 (STEFANONI, 2002, p. 17-18).

Penalizaba la condición de productor de coca. Desde su aplicación se ejecutaron programas de erradicación y sustitución de cultivos. El Estado boliviano fue presionado por el gobierno de los Estados Unidos en su afán de lucha contra el narcotráfico. Las organizaciones cocaleras se cohesionaron con el fin de resistir a la represión, al mismo tiempo que desarrollaban acciones de política de identidad.

\footnotetext{
Su discurso se centró en la defensa de los derechos humanos, en la defensa de la coca como fuente de ingresos pero también como "hoja sagrada”, y por último en la defensa de su propia condición de población pobre estigmatizada por las autoridades estadunidense. (VARGAS; CÓRDOVA, 2003, p.7).
}

Los operativos de represión contra el narcotráfico criminalizaron la condición de campesino, incrementaron su inseguridad para que no participaran en movilizaciones, pero a pesar de la violencia de los operativos: detenciones injustas, muertes y otras violaciones de los derechos humanos, los campesinos continuaron apoyándose en sus organizaciones.

Las investigaciones que analizan el escenario político y social boliviano se centran en la capacidad movilizadora y de resistencia de las federaciones de cocaleros frente a la represión del Estado; sin embargo, se hace poca reflexión sobre los cálculos políticos de la contra-élite liderada por Evo Morales.

El presente artículo propone estudiar el contexto histórico boliviano, analizando la personalidad social y política de Evo Morales, para demostrar que detrás del triunfo de los denominados movimientos sociales existieron liderazgos individuales, particularmente el liderazgo político de Morales que debido a su experiencia de vida, carisma y capacidad de articulación político-social propició el remplazo de las antiguas élites. Dicho de otra manera, el triunfo político de Morales se debe a la lucha entre contra-élite y viejas élites.

\section{LIDERAZGO SOCIO-POLÍTICO DE EVO MORALES}

Juan Evo Morales Ayma, nació el 26 de octubre de 1956 en la comunidad de Isallavi, perteneciente al ayllu Sullka del Cantón Orinoca, Oruro, Archondo (ARCHONDO, 2009, p. 98). Por su historia de vida Morales quedó con la marca de sobreviviente (SIVAK, 2008). Las diferentes biografías coinciden que Morales conoció la precariedad de la vida.

\begin{abstract}
[...] la cruel espera de aquel niño pastor de ovejas y llamas, quien, junto a la carretera y su padre, esperaba el paso de los autobuses, desde donde los pasajeros lanzaban cáscaras de naranja o plátanos, de la cuales ellos extraían la pulpa. (ARCHONDO, 2009. p. 99).
\end{abstract}

Las caminatas de cinco kilómetros para llegar a su escuela por caminos de herradura, las casas de adobe con piso de tierra y techo de paja, la escasa comida y otras características de exclusión social, serían elementos cotidianos y comunes entre los niños de su 
pueblo que cobrarían importancia en su comportamiento político mucho tiempo después cuando tomaría conciencia de su situación de aislamiento y olvido en que su comunidad se encontraba respecto al Estado y sus gobernantes de turno (SARDÁN, 2011, p. 54- 55).

En 1980, los padres de Morales asediados por los desastres naturales emigraron del altiplano a las Yungas, luego a Puerto San Francisco, en el Chapare. Morales a los 23 años sumió su primera labor sindical como secretario de deportes y actas del sindicato San Francisco, en el Chapare. Seis años después, fue electo Secretario Ejecutivo de la Federación del trópico de Cochabamba (a un año de haberse promulgado la ley 1008).

Morales quedó al frente de un movimiento sindical que estaba siendo frontalmente agredido por su propio Estado, se incriminaba a los productores de coca asociándoles con el narcotráfico. Su rechazo a la política exterior estadunidense surgió como una reacción visceral frente a los asesinatos de los cocaleros, pero poco a poco cobrarían mucho más sentido y se asentarían de manera más depurada bajo la tutela de asesores políticos ideológicos (SARDÁN, 2011).

En 1988, Morales y un grupo de sus colaboradores optaron por conformar su propia fórmula política bajo las siglas del Frente Amplio de Masas Antiimperialista (FAMA), (ARCHONDO, 2009, p. 102). Ser consecuente con su dirección política le habría permitido mantener su liderazgo (BUITRAGO, 2006, p. 159-160).

En 1986, en el marco del primer proceso electoral FAMA resultó derrocado. Morales era consciente de su poca experiencia, pero también advirtió de los celos y la competencia de las personas mayores al interior del sindicato, aparentemente Morales era percibido como una amenaza. En 1988 cuando ganó el cargo de Secretario Ejecutivo de la Federación del Trópico de Cochabamba, decidió dedicarse por completo al sindicato. Su eslogan fue: ser honesto y sincero con las bases y estar al frente de las movilizaciones.

Tanto en los años 1980 como en la actualidad su reivindicación indigenista no está exenta de instrumentalismo a la hora de legitimar internacionalmente el cultivo de la hoja sagrada. Las denuncias de Evo Morales coinciden con el apartheid sudafricano de
Nelson Mandela, incluye demandas de inclusión, reconocimiento y posibilidad de acceso al poder de una mayoría nacional segregada por motivaciones étnicas.

Evo Moral se encuentra atravesado por el pragmatismo propio de la cultura sindical y por las posiciones antiimperialistas, cuya base material fueron las luchas entre campesinos y fuerzas sindicales en contra de los militares erradicadores de la hoja de coca. Esta flexibilidad no implica la ausencia de fines ideológicos igualitaristas en los Morales cree genuinamente sobre todo en la mejora de las condiciones de las mayorías populares inmersas en la pobreza que él conoció de niño (STEFANONI, 2006, p. 46-65).

Con el proceso de toma de concienciación colectiva se produjo la identificación de sus enemigos más cercanos, a nivel interno: el Estado, la vieja élite política y las fuerzas militares. A nivel externo: Estados Unidos.

\section{EVO MORALES Y EL MAS}

La década de los 1990, se caracteriza por el reparto de las instituciones estatales en manos de una minoría política, el deterioro del sistema político, el agotamiento de las coaliciones gubernamentales y el encubrimiento de escándalos de corrupción de la élite política. La suma de esas variables propició el desgaste de la vieja élite convencida que la única forma de mantenerse era a través de sus alianzas.

El Instrumento por la Soberanía de los Pueblos (MAS), surgió como órgano político del movimiento campesino en el Trópico de Cochabamba². Para su consolidación contribuyó la protesta social en oposición a las políticas neoliberales implementadas desde 1985.

\footnotetext{
[...] la evolución electoral del MAS, inicialmente marginal en 1997, es un proceso vinculado a la descomposición y crisis de los antiguos partidos políticos de la oligarquía y al ascenso de las luchas populares de los últimos cinco años contra las trasnacionales y neoliberalismo. (ORELLANA AILLON, 2006, p. 31).
}

2. Para profundizar en la discusión sobre el origen del MAS, véase: Stefanoni $(2006,2007)$, Orellana Aillon (2006), Do Alto (2007). 
Las primeras experiencias electorales del MAS, se remontan a inicios de los 1990, cuando la vieja izquierda y el sindicalismo campesino participaron bajo las siglos de Izquierda Unida (IU), los resultados electorales de 1995, le otorgaron primera mayorías en varios municipios del Trópico de Cochabamba, obtuvo 10 alcaldías y 49 concejalías (ZEGADA, 2002). En las elecciones de 1997, participó bajo las siglas ASP (Asamblea para la Soberanía de los Pueblos), logró 4 diputados nacionales, todos eran campesinos. "Entre ellos figuraba Evo Morales quien se destacó por ser el diputado uninominal elegido con el más alto porcentaje de votos del país (61,8\%) Un símbolo de esa nueva simbiosis política entre izquierda y campesinos" (DO ALTO, 2011, p. 99).

A manera de reflexión, lo anterior muestra que la contra-elite inició la lucha por el acceso al poder vía institucional por lo menos 20 años antes de las elecciones generales de 2005, en ese sentido plantea la siguiente interrogante ¿dónde radica la dificultad de analizar el remplazo de la vieja élites considerando la perspectiva elitaria?

i) A la simpatía de los cientistas sociales hacía la cuestión indígena. La Asamblea para la Soberanía de los Pueblos (ASP, posteriormente MAS-IPSP), nació en los años 1990, en la denominada emergencia indígena latinoamericana en la que por primera vez el indígena pasó de la invisibilidad social a sujeto político (MARTÍ; PUIG, 2007); ii) A la misma autodefinición del MAS; y iii) A la relación actual de Evo Morales con las organizaciones sociales a las que políticamente les continúa denominando movimientos sociales.

La autodefinición del MÁS como "un gobierno de los movimientos sociales” desafía el análisis sociológico y político en esta novedosa combinación entre movimiento social y partido político en el poder, sostenido en el fuerte liderazgo carismático del Presidente. (ZEGADA el tal., 2008, p. 45).

Tanto la autodefinición del MAS, como las relación que existe entre Morales y sus bases sectoriales, suelen ser definidas como una relación compleja debido al tipo de discurso político que mantiene la actual cúpula política y la élite cocalera.
El MAS, no tiene una estructura política partidaria, sino que las mismas estructuras del sindicalismo campesino e indígena son las estructura del MAS, por tanto son esas mismas estructuras las que controlan; acá no se manejan las cosas verticalmente, no hay imposiciones. Los dirigentes principales deben cumplir lo que deciden las organizaciones sociales que componen el IPSP». (Entrevista con Evo Morales, Buenos Aires, agosto de 2002; STEFANONI, 2007, p. 20).

El discurso reproducido por las bases sociales es idéntico al que empledo por le gobierno. "El MAS NO es un partido, es un conjunto de movimientos sociales, no queremos que sea un partido, con jefe, estatutos [...]. (Dionisio Núnez, Primer Ampliado de Evaluación de la Gestión del MÁS” (STEFANONI, 2006, p. 20). Uno de los aspectos más llamativo del discurso y el simbolismo utilizado por la actual élite política es haber interiorizado en el imaginario colectivo que el poder político recae sobre los movimientos sociales.

\section{LA LUCHA SOCIAL EN LA CALLE}

El triunfo electoral del MAS, se explica a partir de los siguientes acontecimientos sociales, la Guerra del Agua, del año 2000, y La Guerra del Gas del $2003^{3}$. Al conjunto de estas movilizaciones sociales se les denomina Ciclo de Protestas. Los diferentes trabajos describen los acontecimientos sociales, identifican a los actores involucrados, hacen referencias a las reivindicaciones sociales. Destacan la capacidad de organización de los movimientos sociales para finalmente concluir que el ciclo de protesta favoreció el triunfo electoral del MAS4.

3. En octubre de 2003, La Paz y El Alto fueron escenario de uno de los momentos más críticos para la democracia boliviana desde su restablecimiento en 1982. Decenas de miles de personas protestaron en manifestaciones generalmente violentas en contra del gobierno de Sánchez de Losada. Los sectores sociales se oponían a la intención gubernamental de exportar gas natural por puertos chilenos y a la posible inclusión de Bolivia al Área de libre Comercio para las Américas (ALCA). El proyecto de exportación del gas contaba con el apoyo de la coalición de gobierno y sería ejecutado por las empresas petroleras Repsol YPF, Bristish Petroleum, British Gas, Amoco, Elf y Exxon, instaladas en Bolivia gracias a la Ley de Hidrocarburos aprobada por Sánchez de Losada en 1996 durante su primer mandato. Para profundizar, véase, Arze vargas (2004).

4. "En síntesis, a principios de la actual década los movimientos sociales bolivianos recuperaron su capacidad política y consiguieron influir, como 
Con el propósito de generar un nuevo debate el presente artículo plantea la siguiente pregunta: ¿El denominado ciclo de protesta contribuyó para que se produjera el remplazo de élites o hizo parte de las estrategias de la contra-élite en su aspiración por el reparto de poder?

\subsection{LA GUERRA DEL AGUA DE 2000}

La Guerra del Agua fue una protesta social que en abril de 2000 logró la expulsión del consorcio privado encargado de la gestión del servicio de agua potable y alcantarillado de la ciudad de Cochabamba. El consorcio Aguas del Tunari había sido el único que se presentó a licitación. El grupo de accionista era desconocido, luego se supo que la principal accionista era la empresa Bechtel y que su base de operaciones se encontraba en San Francisco, Estados Unidos.

La Ley 2029, que privatizaba el servicio de agua y las instalaciones de servicios en el área de concesión permitía la expropiación de decenas de sistemas autogestionados que funcionaban en el área rural (MAYORGA; CÓRDOVA, 2008, p. 16-51).

\begin{abstract}
En el origen de los problemas que generaron la crisis se encontraba el proceso de creciente privatización y mercantilización de los servicios públicos y de las tierras. La privatización de los servicios públicos se ha dado generalmente a través del traspaso de empresas públicas a empresas transnacionales, a través del llamado proceso de "capitalización". Como consecuencia del mismo el $50 \%$ de las empresas públicas privatizadas pasa bajo el control y propiedad de las empresas del consorcio transnacional. (TAPIA, 2000, p. 2).
\end{abstract}

El detonante de la protesta social fue el aumento de las tarifas del agua sin que esto significara una mejora en del servicio. Las manifestaciones públicas paralizaron la ciudad y sus alrededores, se extendieron durante varios días en febrero y abril de 2000, fueron apoyadas en muchas otras áreas del país tanto urbanas como rurales. La policía nacional y

en el pasado, en el decurso de los acontecimientos socio/políticos bolivianos. Desde ya, la asunción de Evo Morales a la presidencia de la República, es considerado como resultado de la acción colectiva de los movimientos sociales" (ZEGADA et al., 2008, p. 35). los militares fueron enviados para intentar frenarlas (KRUSE; VARGAS, 2000).

Según Albó (2007), en los estudios sobre protesta social se deberían de diferenciar a las organizaciones sociales participantes. No es adecuado llamarlo movimiento social, sino identificarlos como sindicatos agrarios, juntas vecinales, jubilados, desempleados y cualquier otro sector dispuesto a movilizarse y reclamar frente al Estado.

\begin{abstract}
Consideremos más bien al movimiento cocalero y a las diferentes organizaciones campesinas (las propiamente sindicales y aquéllas basadas en autoridades originarias) como movimientos sociales, por la larga duración y sus objetivos claros. Considerar la "guerra del agua" como un movimiento social, en cambio genera muchas dudas porque, si bien fue dirigida por determinadas cúpulas para revertir la apropiación privada de los servicios públicos las varias agrupaciones que la protagonizaron no tenían intereses comunes Solo el golpe coyuntural del "tarifazo" (la elevación de los cobros por el servicio, hacia fines de 1999) los unió y, una vez derrocado, el movimiento se deshizo muy pronto. (ALBÓ, 2007, p. 156).
\end{abstract}

La Guerra del Agua fue una protesta social espontánea con un objetivo determinado y que una vez lo logró, el movimiento se deshizo. Estuvo encabezada por la Coordinadora del Agua y de la Vida, al inicio conformada por la Federación de Regantes, luego se sumaron los sindicatos de obreros, usuarios urbanos, estudiantes, asociaciones de ambientalistas y sociales e intelectuales.

A manera de síntesis, el denominado ciclo de protesta inició con el rechazo popular por la concesión del servicio de agua a manos de la empresa trasnacional Bechtel en el llamado proceso de capitalización. Las organizaciones populares ${ }^{5}$ encabezadas por la Coordinadora del Agua se movilizaron por el descontento en el aumento de la tarifa del agua, la protesta social fue de tal magnitud que logró que el contrato fuera rescindido por el gobierno.

5. Entre las organizaciones que participaron y ejercieron protagonismo están: la Central Obrera Boliviana, COB, la Confederación Sindical Única de Trabajadores Campesinos de Bolivia, CSUTCB, la Federación Sindical de Trabajadores Mineros de Bolivia, FSTMB, los sindicatos de cultivadores de coca y el Movimiento sin Tierra MST. 
Los diferentes estudios se centran en el papel que jugó la Coordinadora del Agua, pocas veces se menciona la participación de los sindicatos cocaleros del Chapare.

Fue en febrero que a la Guerra del Agua se unió un nuevo e importante aliado, los productores de coca del Chapare, encabezado por su líder Evo Morales. Con los cocaleros, se sumaron años de experiencia en las tácticas de resistencia en contra de las tropas que enfrentaban cuando entraban a destruir sus cocales. "Fueron los cocaleros los que nos enseñaron a usar pañuelos remojados en vinagre para combatir los efectos del gas" dijo un activista de la Coordinadora. El propio Morales se echó a la calle durante esos días, haciendo frente a la policía. (SHULTZ, 2008, p. 29).

La Coordinadora había apoyado las movilizaciones de los cocaleros en el Chapare, ese vínculo facilitó la coordinación del sindicalismo de los cocaleros en el Chapare con el sindicalismo campesino del Altiplano.

La Coordinadora, en particular su líder Oscar Olivera jugaron un rol importante en la construcción de los vínculos entre movimientos y partidos a escala local y nacional. Como resultado nació el proyecto de crear una Coordinadora de los Movimientos Sociales, el denominado Estado Mayor del Pueblo integrado por organizaciones sindicales, movimientos sociales y la izquierda política del MAS (TAPIA, 2008, p. 295-306).

En el contexto de la Guerra del Agua y de los bloqueos del Chapare, Cochabamba y Achacachi, La Paz de 2000, García Linera (2011), analiza la logística (tácticas) desarrollada por las organizaciones populares través de la categoría forma multitud ${ }^{6}$. La logística desarrollada tenía la armazón de poder político alternativo, contaba como punto de partida con asamblea de comunidades (sindicato campesino). Una de las razones, por la que tanta gente pudo mantenerse, luchando por tantos días en las carreteras se sostuvo en el tradicional sistema de turnos mediante el cual cada veinticuatro horas las personas movilizadas de una comunidad eran sustituidas por la de otra comunidad con el objetivo de permitir que las primeras descansaran,

6. Para él, la multitud es una red organizativa bastante flexible, que presenta un eje de aglutinación bastante sólido y permanente, capaz de convocar, dirigir y movilizar a una inmensa cantidad de ciudadanos sueltos. se dedicaran unos días a su faena y regresaran nuevamente a la movilización cuando le tocara su turno.

Por cada cien personas movilizadas en uno de los cien bloqueos hay un círculo de otras mil o dos mil personas que esperan su turno para desplazarse. De ahí el cálculo conservador de que sólo en el altiplano se movilizó cerca de quinientos mil comunitarios aymaras (GARCÍA LINERA, on-line).

El momento culminante de los acontecimientos acorridos entre 2000 y el 2001 fue en el Cuartel General Indígena de Q’alachaca, donde cerca de cuarenta mil aymara se atrincheraron durante semanas a fin de prepararse para un enfrentamiento bélico contra el ejército.

El Ejército Indígena Aymara concentrado en el cuartel era una formación compuesta de pequeños ejércitos regionales y zonales que rotativamente se concentraban en la zona de operaciones al mando de sus propias autoridades, con sus propios mecanismos de abastecimiento y logística militar (piedra, palos, dinamitas y fusiles). Las rebeliones de septiembre-octubre y junio-julio, han sido una guerra simbólica, luchas por la estructura de representación, jerarquización, división y significación del mundo. A medida que los sistemas dominantes-coloniales eran impugnados (GARCÍA LINERA, on-line).

La cita anterior merece por lo menos dos comentarios, el primero, la estructura política alternativa, se dio por la confluencia de intereses de los líderes de las organizaciones sociales. El segundo, las convulsiones sociales no deberían de ser considerada guerra simbólica porque hubo enfrentamiento violento entre manifestantes y fuerzas militares cuerpo a cuerpo.

\section{CONCLUSIÓN}

El presente artículo partió de la siguiente hipótesis, el triunfo electoral de Evo Morales se debe a cálculos políticos en su afán por el reparto de poder. Para probarla se realizó un estudio histórico de los acontecimientos sociales que propiciaron el triunfo político de Evo Morales. De acuerdo a nuestro hallazgo podemos 
afirmar que el supuesto se cumple, ya que la lucha social no sólo perseguía la defensa del uso tradicional de la hoja sagrada, la denuncia de los efectos de las políticas neoliberales, los pactos entre la vieja élite política o la exclusión histórica, sino que además la contra-élite liderada por Morales realizó diferentes estrategias políticas para potenciar el desgaste de la vieja élite.

Evo Morales, se convirtió en la cara visible de la contra-élite, su trayectoria sindical de El Chapare, fortaleció su carrera política. Logró construir una identidad política en contraposición de sus rivales. Mientras los partidos tradicionales defendían la erradicación de la hoja de coca, Morales proponía su legalización y mostraba su rechazo a la política exterior estadunidense en especial a la lucha contra el narcotráfico.

Si bien, nuestro estudio se limitó al análisis de la personalidad política de Evo Morales, la protesta social en la calle y las alianzas entre movimientos sociales y partido político tanto a nivel local como nacional. Es importante considerar que a mayor recrudecimiento de las movilizaciones sociales, los resultados electorales favorecían la carrera política de Evo Morales (ESPINOZA; FRANZ JUNIOR, 2016).

Por último, introducir la categoría de análisis contra-élite podría ofrecer nuevas interpretaciones en las relaciones de poder de las nuevas minorías políticas que logran representar las demandas sociales, articularse en movimientos y competir en la arena electoral a través de partido político.

\section{REFERÊNCIAS}

ALBÓ, X. Bolivia: Avances y tropezones hacia un nuevo país plurinacional e intercultural. En Los pueblos indígenas y política en América Latina. El reconocimiento de sus derechos y el impacto de sus demandas a inicios del siglo XXI, Salvador Martí i Puig (ed.). Barcelona: Fundación CIDOB, 2007. p.335-359.

ARCHONDO, F. ¿Qué le espera a Bolivia con Evo Morales? Nueva Sociedad, n. 202, p.1-12, 2006.
ARCHONDO, F. La ruta de Evo Morales. Nueva sociedad, n.209, mayo-junio, p.82-99, 2007.

ARCHONDO, F. Breve biografía política de Evo Morales. Umbrales 97, p.97-118, 2009.

ARZE VARGAS, C. Las rebeliones populares de 2003 y la demanda de nacionalización de los hidrocarburos: ¿fin de la era neoliberal? Cuadernos del CENDES, año 21, n.56, p.83-103, mayo-agosto, 2004.

BUITRAGO, M.A. El significado de la llegada de Evo Morales al Poder en la República de Bolivia. Nueva Época, Año VI, n.22, p.159-164, 2006.

DO ALTO, H. El MAS-IPSP boliviano, entre la protesta callejera y la política institucional. In: MONASTERIO, Karim; STEFAFONI, Pablo; DO ALTO, Hérve (Ed.).

Reinventando la nación en Bolivia. Movimientos sociales, Estado y poscolonialidad. La Paz: Plural editores, 2007. p.71-108.

ESPINOZA, F. Bolivia: la circulación de sus élites (2006-2014), Santa Cruz de la Sierra: El País, 2015.

ESPINOZA, F.; FRANZ, P. Movilizaciones sociales y partidos políticos: las vías de la contra-élite en Bolivia y Ecuador. Newsletter. Observatório de elites políticas e sociais do Brasil. NUSP/UFPR, v.3, n.13, p.1-17, outubro 2016. ISSN 2359-2826.

GARCIA LINERA, A. La formación de la identidad nacional en el movimiento indígena- campesino. Fe y Pueblo, n.2. 2002.

GARCIA LINERA, A. La potencia plebeya: Acción colectiva e identidades indígenas, obreras y populares en Bolivia. Buenos Aires: Prometeo Libros, 2008.

GARCIA LINERA, A. Las tensiones creativas de la revolución. La quinta fase del proceso de cambio». La Paz: Vicepresidencia del Estado Plurinacional, 2011. 
GARCIA LINERA, A. (mimeo). A. Multitud y comunidad. La insurgencia social en Bolivia. Mimeo. Disponible en: <https://www.insumisos.com/lecturasinsumisas/ Multitud\%20y\%20comunidad\%20en\%20Bolivia.pdf>. Acesso em: 27 jul. 2017.

KRUSE, T.; VARGAS, H. Las victorias de abril: Una historia que aún no concluye. Revista del Observatorio Social de América Latina, CLACSO, p.7-14, 2000.

MARTÍ I PUIG, S. (Ed.). Pueblos indígenas y política em America Latina: el reconocimiento de sus derechos y el impacto de sus demandas a inicios del siglo XXI. Barcelona: Fundación CIDOB, 2007.

MAYORGA, F.; CÓRDOVA, E. El movimiento antiglobalización en Bolivia, procesos globales e iniciativas locales en tiempo de crisis y cambio. La Paz: Plural, 2008.

PÉREZ, C. Tendencias migratorias en las áreas de producción de coca. En: ROA, Mónica (Ed.). Droga y Sociedad. Cochabamba: CERES, 1992. p.28-33.

ORELLANA AILLÓN, L. Nacionalismo, populismo y régimen de acumulación en Bolivia. Hacía una caracterización del gobierno de Evo Morales. Centro de Estudios para el Desarrollo Laboral y Agrario, CedLA, Serie Documento de Coyuntura. La Paz, 2006. p.1-45.

SARDÁN, E. La personalidad política de Evo Morales. ¿El MAS es de izquierda? Estudios y ensayos, Cochabamba: EPRI-CCI, 2011. p.52-59.

SHULTZ, J. La guerra del agua en Cochabamba y sus secuelas. En: SHULTZ, Jim; DRAPER, Melissa Crane (Comp.). Desafiando la globalización, historia de la experiencia boliviana. La Paz: Plural, 2008.
SIVAK, M. Jefazo. Retrato íntimo de Evo Morales. Santa Cruz: El País, 2008.

STEFANONI, P. El nacionalismo indígena como identidad política: La emergencia del MASIPSP (1995-2003). Informe Final del Concurso: Movimientos Sociales y Nuevos Conflictos en América Latina y El Caribe. Programa Regional de Becas CLACSO. 2002.

STEFANONI, P. El nacionalismo indígena en el poder. Revista latinoamericana de Ciencias Sociales, CLACSO, Buenos Aires, julio, Año VI, n.19, 2006.

STEFANONI, P.; DO ALTO, H. La revolución de Evo Morales. De la coca al palacio. Buenos Aires: Capital Intelectual, 2006.

TAPIA, L. Bolivia, la izquierda y los movimientos sociales. En: CHÁVEZ, Daniel; GARAVITO, Cesar Rodríguez; BARRETT, Patrick (Ed.). La nueva izquierda en América Latina, Madrid: Catarata, 2008.

TAPIA, L. Una reflexión sobre la idea de Estado Plurinacional. OSAL, CLACSO, Buenos Aires, Año VIII, n.22, septiembre 2007.

WALDMANN, P. Algunas observaciones y reflexiones críticas sobre el concepto de elite. En: BIRLE, Peter et al (Ed.). Elites en América Latina, MadridFrankfurt: Iberomericana-Vervuert. 2007. p.9-30.

ZEGADA CLAURE, M.T.; TÓRREZ, F.; CÁMARA, $G$. Movimientos sociales en tiempos de poder. Articulaciones y campos de conflictos en el gobierno del MAS. Cochabamba: Centro Cuarto Intermedio, 2008. 
Data da submissão: 25 de Maio de 2017

Avaliado em: 10 de Julho de 2017 (Avaliador A) Avaliado em: 2 de Agosto de 2017 (Avaliador B) Aceito em: 30 de Agosto de 2017
1. Es Politólogo; PhD en Estudios Internacionales e Interculturales (mención internacional) Universidad de Deusto, País Vasco; PhD en Derecho, Universidad Federal do Ceará - UFC; Investigador postdoctoral en Políticas Públicas de la Universidad Federal del Paraná (Brasil) - UFPR; Miembro del Núcleo de Investigación en Sociología Política Brasileña, Universidad Federal del Paraná - NUSP/UFPR; Es miembro del Observatorio de Élites Políticas y Sociales - UFPR, becario CAPES; Es miembro de FLACSO-España. E-mail: espinoza.fran@gmail.com

2. Es estudiante de Ciencias Sociales por la Pontificia Universidad Católica del Paraná - PUCPR; Miembro del Núcleo de Investigación en Sociología Política Brasileña, Universidad Federal del Paraná - NUSP/UFPR, y del Observatorio de Élites Políticas y Sociales; Fue becaria del Programa Institucional Iniciación para docencia por la CAPES, 2016; En la actualidad es becaria de iniciación científica del Consejo Nacional de Desarrollo Científico y Tecnológico/CNPq; Investigadora del área de Ciencia Política, con énfasis en los temas: elites políticas, profesionalización política y reclutamiento político. E-mail: amandafsangalli@gmail.com

3. Es cientista político, PhD en Ciencias Sociales por la Pontificia Universidad Católica de Rio Grande do Sul (PUCRS). Realizó parte de su doctorado en la University of Pittsburgh, a través de doctorado sándwich. Actualmente, es investigador de post-doctorado en Relaciones Internacionales con beca Docfix Fapergs/Capes y miembro del Centro Brasilero de Pesquisas en Democracia (CBPD) de la PUCRS. Email: andregerardi3@hotmail.com 